\title{
Comunicación

\section{Metaforización como vehículo de representación discriminante. Ejemplos de prensa de Guadalajara (principios del siglo XX)}

\author{
GERARDO GUTIÉRREZ CHAM*
}

Desde la perspectiva del análisis crítico del discurso y la pragmática, analizamos las representaciones discursivas en torno a grupos socialmente «problematizados» que aparecen en muestras selectivas que hemos tomado de la prensa de Guadalajara, de principios del siglo XX. Mostraremos la importancia que tenía la metaforización como vehículo de representaciones conflictivas y discriminadoras de ciertos actores sociales, que eran considerados inferiores, problemáticos, amenazantes, indeseables o anormales.

PALABRAS CLAVE: metáfora, asimetría, cuerpo, presuposición, estigmatización.
From the perspective of the critical analysis of the speech and the pragmatics, we analyze the discursive representations around groups socially showed as a problem, that appear in selective samples that we have taken of the Guadalajara's press, of the beginning of the XXth century. We will show the importance that the metaforization took as a vehicle of troubled representations and discrimination of certain social actors, who were considered to be low, problematic, threatening, undesirable or abnormal.

KEY WORDS: metaphor, asymmetry, body, presupposition, stigmatization.

* Universidad de Guadalajara.

Correo electrónico: gcham535@yahoo.com.mx. 
La obra de Lakoff y Johnson (1995) es ampliamente conocida por el enfoque novedoso con que han abordado el tema de las metáforas. A diferencia de los planteamientos clásicos que confinaban el uso de metáforas dentro del dominio retórico y poético del lenguaje, Lakoff y Johnson presentan un modelo dialéctico en el que las metáforas se manifiestan como entidades que impregnan el lenguaje cotidiano y se constituyen en el principal mecanismo, a través del cual entendemos conceptos y realizamos razonamientos abstractos. El enfoque interactivo de la metáfora supone un cambio significativo de atención. En lugar de atender a las metáforas como productos de la actividad artística, o «desviaciones» del sentido literal, han pasado a ser estudiadas como procesos de construcción de significados especiales. Este cambio corresponde en lingüística a un giro de foco, desde la semántica a la pragmática. Actualmente hay gran cantidad de estudios donde se advierte que nuestro lenguaje común es mucho más metafórico de lo que a menudo advertimos, ya que buena parte de la coherencia y el orden de nuestra actividad conceptualizadora común, se basa en el modo en que metaforizamos las estructuras mentales de nuestra experiencia ${ }^{1}$.

El planteamiento base de Lakoff y Johnson muestra que al referir hechos y procedimientos cercanos al entorno de los hablantes, inmediatamente se utilizan expresiones que provienen de otro campo metafórico. No se trata de una relación de equivalencias, sino de un isomorfismo entre dos áreas de experiencia cognitiva. John Searle establece dos grandes grupos que desde su punto de vista abarcan las tendencias de acercamiento al problema de las metáforas. Por una parte están las teorías que desde Aristóteles, han intentado explicar lo metafórico en términos de comparación o similitud entre dos o más objetos, y por otro lado tenemos teorías donde lo metafórico se observa como un proceso de interacción entre contenidos semánticos que aleatoriamente se modifican según las circunstancias de emisión, recepción y contextua-

1 Aunque la bibliografía sobre estudios de metáfora es muy amplia, sugerimos las siguientes obras que, desde nuestro punto de vista, pueden consultarse como referencia para distintos estudios sobre metaforización. Sólo mencionaremos obras consultadas, mas no citadas en este trabajo: Austin (1962); Cameron (2003); Deignan (2005); Gibbs (1994); Giora (2003); Goatly (1997); Goóssens (1995); Orony (1993); Taub (2001). 
lización de los enunciados metafóricos (1995:90). Nos parece que en ciertos aspectos, ambas posturas son complementarias. ${ }^{2}$ Objetos y personas entran en juego no para ser comparados en términos lógicos, sino ser reformulados mediante estrategias semánticas cuyo funcionamiento depende de factores contextuales y pragmáticos. Para nosotros el hecho más relevante es que las metáforas pueden dar expresión a entidades abstractas a partir de otras entidades más concretas, lo cual puede incidir notablemente en la representación, y por tanto, en la percepción de los hechos.

En este trabajo mostraremos la importancia que tenía la metaforización en la representación conflictiva y discriminadora de ciertos actores sociales, que en el discurso de la prensa tapatía de principios del siglo $\mathrm{XX}$, eran considerados inferiores, problemáticos, amenazantes, indeseables o anormales. ${ }^{3}$ En este sentido, las metáforas funcionaban como

2 El mismo Searle se encarga de explicar por qué es factible esta complementariedad. Una metáfora pone en relación dos objetos pero bajo un orden especial. Esto significa que una aserción metafórica no es en toda regla una aserción de similitud. Searle proporciona, entre otros, el siguiente ejemplo: «Ricardo es un gorila» (1995:92). Tal afirmación hace presuponer que Ricardo es alguien feroz, enojón y propenso a la violencia, del mismo modo que también se presupone que los gorilas son feroces, enojones y propensos a la violencia. Entonces, lo que la expresión metafórica quiere decir al oyente es que tanto Ricardo como el gorila son semejantes en ciertos aspectos. Pero una observación más detallada nos hace caer en la cuenta de que esta comparación obedece más a creencias estereotipadas y no tanto a verificaciones derivadas, por ejemplo, de la experiencia científica. Podríamos suponer, como dice Searle, que una investigación etológica demuestre que en realidad los gorilas no son del todo enojones, feroces ni propensos a la violencia, sino más bien animales tímidos y muy sensitivos. Esto no demostraría que una afirmación metafórica de este tipo es una mentira, porque en ciertas situaciones tal expresión funciona bien para expresar ciertas cosas acerca de Ricardo. Entonces, en la expresión Ricardo es un gorila, más que una comparación real, lo que tenemos es un reordenamiento semántico que sirve para expresar algo principalmente de Ricardo y no tanto de los gorilas.

3 El corpus que hemos seleccionado consta de artículos periodísticos que van de 1917 a 1950. Entre los periódicos seleccionados están El Informador (1917), el diario Restauración (1919-1956), La Prensa (1921), Acción Social (1925), El tiempo (1926), El Heraldo (1927), Hoy (1930), Mercurio (1930) y El Jalisciense (1932). Ciertamente con un corpus de esta naturaleza no 
actos de habla especiales, proclives a la consecución de ciertas funciones de refuerzo estigmatizante y discriminador. A manera de ejemplo, veamos una muestra tomada del titular de un editorial aparecido en $E l$ Informador, el 15 de noviembre de 1918.4

(1) «El que se hace gusano no puede quejarse de que lo aplasten»

Hemos querido dar inicio con este ejemplo porque es una muestra típica de agresión verbal, manipulación, sarcasmo y menosprecio sesgado, al que se podía llegar como promotor de conductas validadas desde los poderes hegemónicos. En este titular entran en juego por lo menos dos sentidos metafóricos: $a$ ) hacerse gusano (cualquier persona) y b) ser aplastado por algo o alguien. En ambos casos se verifican las observaciones de Searle (1995) y de Lakoff y Johnson (1995). No es exactamente un gusano lo que está en relación comparativa, sino una serie de representaciones simbólicas muy negativas asociadas a los gusanos (seres que se asocian a la suciedad, que se arrastran, que tienen aspecto desagradable, etc.). Tampoco es exactamente un pie o cualquier otro objeto físico, lo que está en asociación comparativa, sino el acto simbólico de aplastar con todo lo que ello presupone (oprimir violentamente, castigar, humillar, eliminar, etcétera).

Ambos sentidos metafóricos contribuyen al refuerzo de una intención general, por parte de quien escribe, ya que se trata de denunciar la

damos cuenta de un espectro muy amplio de lo que ocurría a principios del siglo XX. Se han extraído notas en las que se aborda a los grupos sociales que nos interesan: mujeres, indígenas, indigentes y homosexuales, entre otros. El muestreo no será probabilístico, sino que obedecerá más bien a criterios de pertinencia temática. Creemos que con ello se garantizará un análisis de corte cualitativo.

4 Esta nota, al igual que las otras que seleccionamos para el presente artículo, forman parte de un corpus mayor sobre actos violentos o discriminatorios. A fin de que nuestro corpus diera muestra de un seguimiento periódico, hemos seleccionado las notas con intervalos de quince días, a partir de del primer número aparecido en El Informador, en 1917. Esta periodicidad obedece a un criterio aleatorio de selección temática, pues no es de nuestro interés estudiar un evento en particular, sin un tema: la violencia. 
supuesta falta de valentía y arrojo entre muchos habitantes de pequeñas poblaciones aledañas a Guadalajara, quienes debían hacer frente a gran cantidad de abusos y atropellos de las autoridades locales. Tal acusación ocurre, a pesar de que, tal y como se especifica en el texto, muchos de ellos «no dan sus nombres por no ser víctimas de un atentado».

Uno de los primeros aspectos que llaman la atención en el corpus de textos que hemos recogido, es el hecho de que muchas metáforas parecen concebidas en función de un doble juego de deslinde y asignación de culpa. Efectivamente, si observamos el sintagma inicial del ejemplo (1): El que se hace gusano, encontramos aquí un primer proceso metafórico bifuncional, tanto de deslinde como de culpabilidad asignada. El sujeto locutor, mediante el impersonal se, toma distancia y además hace que anafóricamente el propio sujeto de quien se habla, aparezca como el único responsable de los males que padece. ${ }^{5}$ Ahora bien, tal vez lo más extraño y complicado de este proceso es que los padecimientos autoconferidos no están explícitos en el ejemplo (1), en cambio aparecen subsumidos, sugeridos, mediante una serie de implicaciones pragmáticas y semióticas, generadas a partir del sustantivo gusano, cuyas resonancias negativas, desde hace siglos permanecen arraigadas en el imaginario colectivo de nuestra cultura. 6 Se produce entonces un efecto metafórico, donde se pretende que las atribuciones negativamente mitificadas de un animal sustituyan la explicitación de ciertas actitudes negativas adjudicadas a las personas, como serían por ejemplo la falta de valentía, la ausen-

5 A propósito de expresiones anafóricas, tanto reflexivas como recíprocas, puede consultarse el trabajo exhaustivo de Carlos Peregrín Otero (2000: 1429-1509).

6 Jean Chevalier y Alain Gheerbrant afirman que dentro de la evolución biológica, el gusano representa los estados previos a la descomposición (1995:546547). El término «gusano» no representa a un tipo específico de animal, sino que hace alusión a muchos animales de cuerpo blando, casi siempre alargado y carente de extremidades bien desarrolladas. Por tanto, no es extraño que los animales designados como gusanos tengan mala reputación, ya que se asocian con los estados larvarios de la vida y se considera que son intrusos que vienen a arrebatar o a carcomer la carne del ser querido. No es casual que una de las imágenes más tabuizadas en nuestra cultura sea la de un cadáver infestado de gusanos. A ello debemos agregar el aspecto blando, viscoso y el hecho de que vivan ocultos bajo tierra. 
cia de compromiso, «el ocultamiento», etc. De manera que en este titular el locutor opera bajo principios de asociación simbólica tomados, tanto de la experiencia cotidiana, como de los sistemas de representación estereotípicos. No tendría el mismo efecto negativo ni el mismo sentido despectivo el mismo enunciado, si en vez de gusano, el locutor hubiera puesto paloma, ya que los sentidos favorables o desfavorables de un concepto metafórico, no pueden usarse arbitrariamente, pues forman parte del acervo cultural, propio de una sociedad (Lakoff y Johnson, 1995:7778). Pero los efectos pragmáticos de las construcciones metafóricas no sólo se limitaban a orientar maneras específicas de representar a las personas. Consideramos que las metáforas también orientaban maneras de actuar, como en el ejemplo (1), donde se implica, de manera indirecta, que se podían cometer abusos impunemente contra todos aquellos que se quejaran de manera anónima.

Consideramos que el hecho de inducir a representar, así como a actuar negativamente contra grupos de personas, sólo podía lograrse mediante la consecución de un discurso que ante los ojos de los lectores apareciera como algo coherente, tanto a nivel formal, como a nivel de sentido. Para ello era determinante que la distribución de los enunciados metafóricos guardara una cierta apariencia de lógica constitución encadenada. De este modo una metáfora podía funcionar como un primer item de causación, ligado a otras metáforas subsiguientes. Veamos de nuevo el ejemplo (1):
A. «El que se hace gusano
B. No puede quejarse
C. De que lo aplasten»

En estas metáforas A funciona como causa de B y C. La condición de gusano aparece como la causa que impide quejarse, así como la causa implícita de que alguien pueda ser susceptible de padecer abusos. A su vez A, B y C están correlacionadas a nivel macro con otra serie de metáforas distribuidas al interior de esa nota. En el primer párrafo, donde se hace mención de la correspondencia con quejas anónimas, que frecuentemente se recibían en El Informador, volvemos a encontrar un enunciado con elementos figurativos de causación: 
(2) «Naturalmente toda esa literatura quejumbrosa y amiedada va a dar al cesto de los papeles inútiles y no volvemos a acordarnos de ella» (El Informador, 15/XI/1918).

Es notable la correlación de sentido entre los elementos figurativos (naturalmente, quejumbrosa, amiedada, va a dar al cesto de los papeles inútiles). En este último ejemplo se genera la impresión de que el motivo por el cual se ha desechado la correspondencia física y mental, tiene su origen en el carácter quejumbroso que los dueños del periódico perciben al interior de los textos. Lo importante, a nuestro modo de ver, es que en ambos casos se hace patente el esfuerzo por generar la apariencia de que se trata de causas y efectos vinculados directamente entre sí, bajo la influencia de un orden natural, como bien se asienta mediante el adverbio naturalmente. Después de todo, construir metáforas significa en sentido estricto, llevar a cabo movimientos conceptuales o mapeos desde un dominio de origen a otro de destino (Parente, 2000:3). Entonces, en casos como (1) y (2), las expresiones metafóricas concretas funcionan como manifestaciones superficiales de mapas conceptuales reacomodados de manera que los receptores podían percibir esquemas de representación desfavorable enfocados hacia las acciones de los demandantes, y esquemas de representación favorable enfocados hacia el gobierno.

Ahora bien, de manera más puntual, este reacomodo o desplazamiento conceptual incide por lo menos en tres niveles de orden pragmático que llamaremos refuerzos.

1. Refuerzo focalizador: el lector es inducido a centrar su atención sólo en aquellos aspectos considerados relevantes por diversas instancias de autoridad.

2. Refuerzo categorizador: el lector es inducido a concebir aquello de lo que se habla en función de categorías predeterminadas.

3. Refuerzo orientador: el lector es inducido a proyectar una orientación sobre algo que no posee orientación de manera inherente. Por ejemplo, considerar que las personas pueden ser instancias susceptibles de trasformarse en otras instancias 
A su vez consideramos que estos tres niveles también influían de manera determinante a fin de generar la impresión de que los supuestos implicados en las metáforas eran verdaderos. Lakoff y Johnson se suman al criterio ampliamente compartido, en el sentido de que lo considerado verdadero tiene más probabilidades de ser aceptado e incorporado a nuestra concepción de lo normal. En este punto conviene tener en cuenta los planteamientos del lingüista Benjamín Lee Whorf, quien desde 1956 mostró cómo es que en muchas ocasiones los conceptos metafóricos se utilizan porque en el rango de selectividad se presentan como el medio más accesible que tenemos para expresar una abstracción y presentarla a los demás como un hecho constatable, verdadero. Entonces, las metáforas no necesariamente funcionan como un medio a través del cual se desea conseguir algún efecto especial. ${ }^{7}$ Visto así, la metáfora adquiere categoría de constructo funcional. He aquí, uno más, entre muchos refuerzos socialmente orientados a presentar el lenguaje metafórico en términos de secundariedad o desvío, respecto al lenguaje literal. Pero si aceptamos tal jerarquización deberíamos presuponer entonces que si algo se dice figurativamente, también debería tener su equivalente de modo literal, cosa que parece más bien una aporía, pues tal y como ha señalado Lee Whorf, ya citado, muchas veces se recurre a conceptos metafóricos porque no se encuentran otros medios lingüísticos disponibles. Buena parte de nuestro lenguaje cotidiano considerado literal, también está estructurado por metáforas conceptuales (Parente, 2000:5).

\section{EL CUERPO}

Dado que el uso de metáforas en nuestro lenguaje cotidiano es tan frecuente y reiterativo, los hablantes tendemos a suponer que surgen mediante procedimientos trasparentes, automáticos y en todo caso, no

\footnotetext{
7 Esto se ve en casos como perder el trabajo, vencido por el dolor, no pudo contener más su rabia, etc. Si nos planteáramos la posibilidad de sustituir estas expresiones por otras con sentido menos figurado y más literal, probablemente descubriríamos que la posibilidad de sentidos empieza a abrirse de un modo insospechado, a tal grado que lo expresado pasa a ser otra cosa.
} 
conscientes. De ahí la creencia común de que sólo aquellas metáforas literarias merecen atención especial. Sin embargo, desde la nueva perspectiva cognitiva, cualquier procedimiento de metaforización automática debería estudiarse más en detalle, pues existen marcadas evidencias que demuestran interdependencia entre metáforas cotidianas y experiencia corporal inmediata (idem). Esta vinculación estaría marcada por lo que Mark Turner ha denominado «experiencia necesaria», es decir, todo aquello que facilita la coacción de esquemas mentales del tipo arriba, abajo, delante, detrás, verticalidad, recipiente, etc. 8 A nuestro entender, este aspecto no ha de pasarse por alto, ya que un sustrato de esta «experiencia significativa» lo vemos incorporado en enunciados metafóricos donde los otros aparecen representados como personas y grupos en permanente minusvalía respecto a ese nosotros, instancia desde la cual se habla. En este sentido hemos observado que de manera recurrente tiene gran importancia un fenómeno ya estudiado por Strawson (1989), quien sostenía que una parte sustancial del sentido metafórico está dado por un particular de base que son los cuerpos. Esto supone para nuestro caso, que en los procedimientos de representación conflictiva y discriminante, son decisivas las nociones implícitas relativas al funcionamiento espacio-temporal de los cuerpos, entre los cuales es indudable que de un modo egocéntrico se ha privilegiado al cuerpo humano. Veamos un ejemplo:

(3) «Los que sufren injustificadas persecuciones, los que son víctimas de atentados, los que ven mal administrada la circunspeccción en que viven, debieran armarse de fortaleza»

Aquí se implican diversas condiciones abstractas, vinculadas con el cuerpo, ya que en términos de Lakoff y Johnson, se trata de la metáfora bélica de alguien que utiliza algo de su cuerpo para tomar armas en defensa. Una serie de condiciones abstractas generalmente asocia-

8 Valga señalar que este proceso tiene lugar desde nuestras primeras experiencias corporales y espaciales. Véase Turner, Mark (http://www.oregon/metaphor). 
das con la voluntad, el carácter, la decisión, simbólicamente adquieren categoría de armas. De manera subsidiaria estas asociaciones parecen ancladas a una metáfora de base que podríamos expresar de la siguiente manera: los fuertes poseen instrumentos para defenderse.

En el siguiente ejemplo el cuerpo aparece proyectado desde un sustrato simbólico:

(4) «...y elevar virilmente sus quejas, en vez de ocultarse y de pretender sacar las castañas con la mano del gato» (El Informador, 15/XI/1918).

Nótese como está aprovechada la sistematicidad espacializadora de las metáforas de base (elevar, ocultarse, sacar). En el primer sintagma elevar virilmente se produce una doble correlación de fuerzas isotópicas de base orientacional: Fuerza isotópica $1 \rightarrow$
(FI1) $\quad \begin{aligned} & \text { de espacio (elevar = lo bueno es arriba / } \\ & \text { lo malo es abajo). }\end{aligned}$ lo malo es abajo).

Fuerza isotópica $2 \rightarrow$ cultural ideológico (virilmente $=$ lo fuer(FI2) te está ligado al cuerpo del varón / lo débil está ligado al cuerpo de la mujer).

Tanto en este, como en otros casos, el procedimiento de manipulación metafórica está vinculado a series prototípicas de amplia circulación social. Basándose en sus experimentos, Eleanor Rosch (1977) concluyó que las personas no categorizamos cotidianamente en términos de teoría de conjuntos, sino en términos de prototipos y parecidos de familias. Esto en el plano físico, pero coextensivamente las clasificaciones prototípicas, de algún modo abarcan también otras series de cualidades cognitivas y afectivas, pues en un discurso no sólo identificamos personas y objetos, además intentamos adscribirlos a series compartimentadas de valoraciones subjetivas del tipo ...es buena persona, ¿...será inteligente?, ¿...tendrá aficiones conservadoras? Tales apreciaciones ayudan para que el complejo de propiedades simultáneas pueda ser más 
accesible a nuestra experiencia. Tengamos en cuenta que la recurrencia de clasificación prototípica en nuestra vida cotidiana emerge constantemente.

De manera esquemática, sólo para fines de estudio, diremos que las clasificaciones prototípicas correspondientes al plano físico son de primer nivel debido a factores icónicos, ${ }^{9}$ mientras que las categorizaciones axiológicas serían de segundo nivel, pues están mediadas por elementos de apreciación que no dependen de estímulos sensoriales, sino cognitivos, como valoraciones asumidas, relaciones afectivas, prejuicios, etc. Ahora bien, es importante señalar que las categorizaciones prototípicas, derivadas de secuencias metafóricas suelen aparecer orientadas hacia objetivos específicos de orden pragmático, pues además de los objetivos primarios, implicados en cualquier metáfora, tales como comprender un concepto y otorgar nuevos significados, en nuestro corpus se hace evidente que muchos enunciados metafóricos forman parte de construcciones ideológicas mayores como el señalamiento y la estigmatización. De manera que al denigrar a personas consideradas anormales, indirectamente se intentaba mitigar cualquier alteración de las percepciones sociales consideradas normales, justas, deseables. He aquí otro mecanismo de poder. Veamos algunos ejemplos de nuestro corpus, donde el plano metafórico sirve como eje orientador de anclajes metalingüísticos al servicio de preconstruidos sociales orientados a representar negativamente a los homosexuales.

(5) «Partida de sujetos afeminados detenida ayer por la policía»

(6) Una «Garzoniere» que un grupo de afeminados tenía en la calle de Morelos número doscientos veintiocho fue descubierta ayer por la policía llevándose a cabo algunas aprehensiones de conocidos afeminados»

9 En la iconicidad intervienen factores de semejanza, lo cual implica hablar de contigüidad. En las metáforas la iconicidad es un componente esencial, ya que intervienen factores de réplica isomórfica (Sebeok, 1996: 98-99). Dado que una condición de iconicidad es la semejanza, un texto se vuelve más icónico en la medida en que proporciona más rasgos pertinentes de relación y semejanza con algún objeto identificado. Así entre la casa y la casa de Alberto, concederíamos mayor iconicidad al segundo ejemplo. 
(7) «Uno a uno fueron llegando los invertidos, los que se entregaron a varios juegos de mesa, a ingerir vino y a otras cosas más...»

(8) «Claro que ninguno de ellos quiere confesar su delito, pero el haber sido sorprendidos in fraganti e identificados por algunos de los mismos dio la certeza de que se trataba de hijos de la desaparecida Sodoma y Gomorra»

En este caso los preconstruidos metafóricos se derivan de varias comparaciones elididas con siglos de vigencia. Parecen indicar que si una persona $x$ es homosexual, equivale a decir que desde el punto de vista del enunciador, cuando esa persona tiene $n$ número de propiedades negativas, también pertenece a grupos sociales con $n$ número de cualidades negativas. En todo caso se trata de una falacia convencional en la que a ciertos antecedentes se asignan ciertos consecuentes sin que necesariamente medien relaciones de implicación natural. Eva Feder considera precisamente que el nivel metafórico, desde un punto de vista pragmático ha de verse más como un fenómeno especial de predicación, que abre la posibilidad a nuevas implicaciones, casi siempre a partir de modelos prominentes, entendidos como aquellos rasgos de orden subjetivo que son sintetizados, reducidos, cosificados y manipulados como si fueran piezas móviles de recambio (1987:181).

En las oraciones (5), (6) y (7) las implicaciones atributivas que se desprenden de los adjetivos afeminado e invertido, adquieren nuevas connotaciones a partir de ciertos rasgos de sobresignificación negativa, como la alteración de los regímenes naturales, que indudablemente en aquella época tenían mucha importancia, entre otras cosas, debido a la hegemonía de los valores religiosos. Desde esta perspectiva no parece extraño que en (8) el juego metafórico-estigmatizante esté formado por la evocación bíblica de Sodoma y Gomorra. Pero además, como ocurre en muchos casos, (5), (6), (7) y (8) son ejemplos donde las fuerzas estigmatizantes e irónicas de los predicados implicados dependen de los sujetos primarios que también han sido constituidos figurativamente en colectivos que refuerzan la orientación negativa. Eva Feder se refiere a este hecho como un fenómeno de tensión entre sujetos y atributos. 


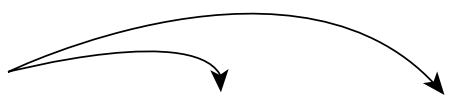

(5) «Partida de sujetos afeminados detenida ayer por la policía»

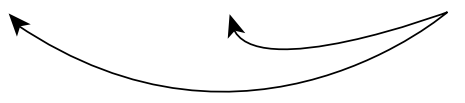

(7) «Uno a

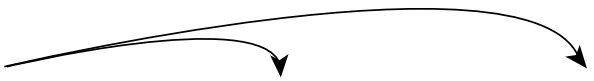

\begin{tabular}{l|l|l}
$\begin{array}{l}\text { «Uno a } \\
\text { uno fueron } \\
\text { llegando }\end{array}$ & $\begin{array}{l}\text { los que se entregaron a } \\
\text { varios juegos de mesa, } \\
\text { a ingerir vino y a otras } \\
\text { cosas más...» }\end{array}$
\end{tabular}

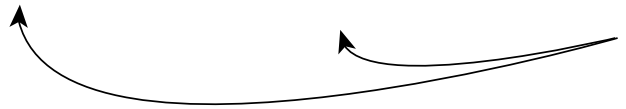

Estos ejemplos, también nos han servido para observar un hecho ya señalado hace muchos años por Beardsley (1958): los grados y jerarquías de complejidad conativa que se producen entre nominaciones y predicados metafóricos, están dados por toda la serie de sobresignificaciones que los receptores en cada contexto son capaces de otorgar, bajo las reglas restrictivas de los propios contextos. Lo importante, para nosotros, es que este hecho interactivo no puede ser del todo controlado, ya que las tensiones de sobresignificación metafórica entre sujetos y predicados sólo pueden ser preservadas en la medida en que la significación literal no está plenamente garantizada. Si el enunciado (5) «Partida de sujetos afeminados» fuera tan restrictivo a nivel semántico, entonces el sentido figurado acabaría por diluirse igual que la crítica implícita hacia personas homosexuales.

Ahora bien, situándonos contextualmente en una sociedad que aún vivía sumergida en un clima de asfixia moral y religiosa, no es de extrañar que estos juegos metafóricos de carácter ironizante no sólo permitieran 
exhibir los pormenores de algo considerado grave, como la homosexualidad, sino que además la metaforización, montada sobre un registro de lo moral, cumplía funciones de advertencia pedagógica en contra de grupos considerados enemigos, o por lo menos indeseables sociales (Foucault, 2001:201). De manera que adjetivos metafóricos como afeminado e invertido en los enunciados anteriores, refuerzan la serie de evocaciones negativas hacia personas que por alguna razón pasan a ser consideradas como creaturas híbridas o malformadas. Aunque no es propiamente nuestro tema, cabe recordar que durante siglos, los homosexuales han sido condenados, perseguidos, estigmatizados y catalogados como «enfermos».10 Un hecho de gran importancia derivado de estas apreciaciones es que bajo ciertas circunstancias y en ciertos ámbitos de receptividad, los conceptos de afeminado e invertido podían volverse sinónimos de «degenerado», «aberrante» $\mathrm{y}$ «delincuente». De una conceptualización abstracta se pasa al estereotipo funcional. Jon Barwise y John Perry asumen el hecho de que un concepto «tipo» suele introducir otra serie de entidades conceptuales que de algún modo «se apoderan» de los individuos facilitando la conformación de «roles» (1983:71-72). Aquí es muy importante considerar factores de relativización, ya que los roles atribuidos a las personas no siempre se comportan del mismo modo. En un mismo evento los actores sociales pueden estar cumpliendo simultáneamente varios roles. Pensemos en la situación donde una persona es detenida por la policía y llevada ante un juez. Para efectos valorativos será importante saber si ese hombre es mayor de edad, si está casado, si tiene empleo, si es un vecino de la localidad o si es inmigrante. Incluso, aún en estos casos, donde debería influir en mayor medida la apreciación desinteresada de los acontecimientos, es del dominio común el hecho de que en los juicios legales tiene gran influencia la fuerza de los estereotipos sociales. Nuestra perspectiva cotidiana fácilmente puede hacernos creer que las relaciones entre eventos y actores son estables, ya que reiteradamente estamos expuestos a enormes dosis de construcciones discursivas, empeñadas en relacionar a

10 Valga el siguiente dato: en el siglo XIX el neuropsicólogo alemán Richard von Krafft-Ebing concluyó que la homosexualidad debía ser tratada como una «degeneración neuropática hereditaria». Véase «homosexualidad», en Enciclopedia Microsoft Encarta 2001. 
ciertos actores con roles muy determinados, aunque de un modo irónico, Barwise y Perry llaman «indeterminada» al conjunto de esta asociación falaz (ibid.:80).

\section{PRESUPOSICIÓN}

Por otra parte concedemos relevancia a un aspecto señalado por Eva Feder en el sentido de que las metáforas proporcionan indicios «sintomáticos de diagnóstico» respecto al objeto (1987:187). Esta terminología tomada del argot médico nos sirve para indicar que a través de una metaforización se establece un conjunto de redes presuposicionales que intentan dar cuenta de una serie amplia de maneras de ser tan abarcadoras como el carácter de las personas, costumbres, afinidades, competencias, etc. A diferencia de los procesos comparativos geométricos, en que un rasgo $a$ es equidistante de uno $b$, y viceversa, en los rasgos de atribución semántica las relaciones son asimétricas y variables según los contextos, aunque lo importante es que esos rasgos son suficientes para establecer juicios de valoración basados en modelos. Así, en muchas notas de nuestro corpus encontramos gran cantidad de atribuciones metafóricas que, mediante un complejo sistema de rasgos implicados, podían generar en los lectores un conjunto amplio de redes presuposicionales que permitían fácilmente clasificar a las personas en grupos conflictivos. En una nota del viernes 25 de marzo de 1938, de $E l$ Informador, se hace referencia al caso de una mujer que fue golpeada por su pareja al llegar a casa, pues lo encontró «hecho un gorila». La situación contextual permite descartar cualquier relación de equivalencia entre sujeto y rasgo atribuido, es decir, como lectores damos por hecho que el locutor no quiere decir que esa mujer al llegar a casa encontró a su marido trasformado literalmente en un simio enorme. Obviamente se trata de mostrar que se encontró ante una persona enfurecida, violenta y dispuesta a golpear. Este es un caso típico de rasgos negativos proyectados $(r n 1, r n 2, r n 3 \ldots)$ en forma de predicados implícitos. Se trata del famoso «dominio de la incongruencia» referido por Ortony (1975), donde lo relevante es la puesta en juego de atributos que no son los mismos, pero se comportan de manera similar. Se produce entonces un isomorfismo estructural, a nivel de los dominios atributivos. Vale la 
pena señalar que el énfasis de la similitud está orientado hacia los atributos, mucho más que hacia los sujetos. Además, señalemos que el rango de selección atributiva no es del todo arbitrario, sino que responde a una estrategia de semanticidad estratégica. A fin de enfatizar el grado de violencia al que puede llegar un hombre parece admisible la comparación con un gorila, ya que ambos pueden ser feroces y violentos como pocos, mas no con un ganso, mucho menos con una gallina. En efecto, dentro de la teoría contextualista, especialistas como Goodman (1984) y Scheffler (1979) se han referido al hecho de que los vehículos metafóricos proveen un esquema de rasgos que funcionan como etiquetas concentradoras de sentido. Por tanto, en una metáfora no funciona cualquier clase de vehículo, ya que el nuevo sentido, otorgado por los oyentes es guiado por el campo habitual del que se ha tomado referencia. Si volvemos al último ejemplo observamos que gorila actúa como vehículo desencadenante de múltiples sentidos, todos ellos derivados de atribuciones aparentemente reales y estables asignadas a los gorilas (fuerza, irritabilidad, disposición al ataque, entre otras). Aún no se precisa del todo cómo operan los sentidos literales y los roles contextuales. El hecho es que en el proceso metafórico, los sentidos atribuidos en función del contexto están supeditados a un «centro duro» de significación «words have a permanent meaning by wich they designate some referents and not others» (Benveniste, 1987:112). Nos importa destacar que simultáneamente interactúa ese centro duro de significación y la sobresignificación generada por la comparación metafórica.

\section{METÁFORA Y COHESIÓN}

Otra característica de las metáforas en nuestro corpus que nos interesa poner a discusión es el destacado papel que desempeñan como pequeños ejes articuladores de cohesión textual. Partimos de la idea de que un texto es un conjunto de unidades de significación relativa que operan mediante relaciones jerárquicamente estructuradas. Si mantenemos la perspectiva de que las metáforas son construcciones cognitivas, es indudable que influyen en los esquemas de repetición de las estructuras enunciativas, ya que entre otras propiedades, pueden manipular estados de cosas, situaciones y objetos. 
Lakoff y Johnson, al hablar de las metáforas orientacionales hacen hincapié en la fuerza organizadora de conceptos en términos de otros conceptos (1995:50). Cuando se trata de términos que implican orientaciones espaciales del tipo arriba-abajo, dentro-fuera o delante-detrás realizamos proyecciones de nuestras percepciones sensomotrices. A nivel textual encontramos que la distribución de esta clase de metaforizaciones hace funciones de hilo conductor, a través del cual percibimos series de representaciones abstractas como si fueran una especie de flujo en movimiento. Específicamente en el caso de textos donde se habla de grupos considerados conflictivos, las metáforas orientacionales ayudan a intensificar, de manera notable, las sensaciones de amenaza o acecho, por parte de estos grupos, a lo largo de todo el texto. Como ejemplo tomamos un pequeño reportaje publicado en el diario El Informador, el 6 de octubre de 1917. En este reportaje se reconoce explícitamente que las clases trabajadoras de la época sufren a causa de la pobreza extendida. En el primer párrafo encontramos una pequeña serie de sintagmas metafóricos que enfatizan la exterioridad negativa de la pobreza:

(9) «La mendicidad en Guadalajara

Una iniciativa que puede fácilmente llevarse a la práctica.

Ciertamente la situación por la que atraviesan nuestras clases menesterosas no es nada halagadora: escasea el trabajo, la miseria asoma su faz lívida y, aunque no entra de lleno con su cohorte de funestos males, es indudable que nos acecha»

Puede apreciarse la distribución de un esquema verbal-metafórico ligado entre sí, de manera que en conjunto, el lector percibe un proceso de situaciones y estados en movimiento, precisamente a través de verbos de movimiento en un presente que parece permanentemente actualizado: atraviesan, asoma, entra, y verbos que expresan estados desfavorables o amenazantes que afectan a todos los receptores: escasea y acecha.

Ahora bien, si en esta parte inicial, el locutor se incluye como parte afectada por la pobreza, pronto se deslinda respecto a la condición, al estado y a las actitudes que asumen «los pobres», mediante metáforas ontológicas (Lakoff y Johnson, 1995:63-70). 
(10) «Sin embargo, por duros que estén los tiempos no lo son a tal grado para que se haya desarrollado la mendicidad con tan vigoroso empuje»

Es de notar como la vida cotidiana, metaforizada ontológicamente con el sustantivo los tiempos, puede representarse como una entidad que tiene consistencia dura, cuyas resonancias culturales generalmente han estado asociadas con lo que es difícil de modificar. Otra estrategia de deslinde utilizada consiste en enfatizar el hecho de que la pobreza ha aumentado gracias a características intrínsecas a su propia condición, tal y como puede ocurrir con los seres vivos, cuando sufren enfermedades imputables a procesos degenerativos internos, ajenos a la propia voluntad. Así, se genera la sensación de que las condiciones contextuales de la pobreza y los sujetos que la conforman, no han crecido espontáneamente, sino que se han desarrollado, lo cual implica procesos interiores de constitución, crecimiento y diferenciación, entre otros. Además, en este mismo sentido el locutor puede enfatizar las causas de la miseria, mediante visiones trágicas, por ejemplo, vinculando campos semánticos provenientes de nuestros ancestrales temores hacia la visión de un cadáver, como se pone de manifiesto en los siguientes ejemplos:

(11) «la miseria asoma su faz lívida»

(12) «es indudable que nos acecha»

En estos casos, la manipulación metafórica permite reconfigurar abstracciones mediante diversos sentidos de lo corporal. En (11) y (12) el foco está dirigido hacia el rostro, lo cual no es del todo arbitrario, sino que obedece a un procedimiento jerarquizador ampliamente compartido en nuestra cultura, hacia una clase de recepción semiótica del cuerpo. Para los seres humanos el rostro ha sido, desde hace siglos, receptáculo de identidad. ${ }^{11}$ En el apartado anterior mencionamos que las clasificaciones prototípicas correspondientes al plano físico son de primer nivel debido a factores icónicos. Esto hace que el discurso trascienda el plano

11 Sobre el estudio semiótico del rostro, pueden consultarse los siguientes trabajos: Ekman et al. (1971); Andrew (1965); Argyle (1969); Davey (1970). 
exclusivamente lingüístico y se generen nuevas herramientas de acceso a otros dominios cognitivos, donde también se satisfacen abstracciones conceptuales de representación.

Puede decirse entonces que a partir de relaciones intersubjetivas, las metáforas abrían acceso a otros niveles de objetividad, ya que en muchos casos era posible, a través de enunciados metafóricos, promover el entendido de que lo abstracto puede ser trasformado en algo mucho más visual y objetivo:

\begin{tabular}{ccc}
\hline $\begin{array}{c}\text { (11) la miseria } \\
\text { (abstracto) }\end{array}$ & $\longrightarrow$ & $\begin{array}{c}\text { asoma su faz lívida } \\
\text { (objetivo) }\end{array}$ \\
\hline
\end{tabular}

Ahora bien, en estos casos entendemos el procedimiento metafórico como una técnica especial de conocimiento autorreferido, ya que el texto abandona, por decirlo así, el nivel de aprehensión de lo real, a fin de referirse al propio texto. El ejemplo (11) muestra cómo la predicación metafórica forma parte de un texto autorreflexivo, autocontextualizado, donde el sentido del enunciado no depende exclusivamente de la especificidad contextual inmediata, sino de la globalidad de todo el texto, de su macroestructura. Wolfgang Raible valiéndose de los principios de la Gestaltheorie o teoría de los conjuntos estructurales, afirma que «las oraciones por sí mismas no tienen sentido si no funcionan en un conjunto superior, por ejemplo, en un conjunto textual o situacional» (2004:20) .

En este sentido, en nuestro corpus son muy importantes las estrategias cohesionadoras de sentido, tanto anafóricas como catafóricas. Cuando tenemos una metáfora de representación negativa, es porque anteriormente ya había aparecido un item de significación semejante. De igual modo, una metáfora de representación negativa, también anticipa a distintos niveles, lo que vendrá en el discurso.

(13) «Hay calles que parecen haberse atraído sobre sí a toda la corte de los milagros, y difícilmente se recorre una acera sin que el transeúnte se vea asaltado por una legión de mendigos verdaderos y falsos que piden, ruegan, importunan y son capaces de acabar con la paciencia que tuviera el santo del muladar» 
Para entender el sentido de los sintagmas metafóricos subrayados, es necesario recurrir, por lo menos a una serie de elementos textuales proporcionados anteriormente, los cuales nos permiten inferir que este fragmento también habla de la pobreza y el desprecio hacia los pobres. Véanse los ejemplos (9), (10) y (11). A su vez, la serie metafórica en el ejemplo (13) constituye un hilo cohesionante, sobre todo a nivel orientacional. Estas metaforizaciones eran orientadoras; ayudaban al lector a saber de qué, de quiénes y en qué forma se iba a seguir hablando. Colateralmente, a través de estas metaforizaciones, se podía influir para que los lectores se formaran o reafirmaran sus percepciones negativas, en apariencia constitutivas de los pobres en Guadalajara. Se trata de un factor de cohesión actancial. Un mismo grupo de sujetos (los pobres) es valorado y representado negativamente, mediante series enunciativas, donde lo metafórico juega un papel muy relevante para generar evaluaciones, señalamientos y estigmatizaciones a lo largo de todo el discurso. Veamos las siguientes agrupaciones de sentido inferencial distribuidas a lo largo del mismo reportaje publicado en el diario El Informador, el 6 de octubre de 1917.

\begin{tabular}{l|l|l}
\multicolumn{1}{c|}{$\begin{array}{l}\text { Actores } \\
\text { sociales }\end{array}$} & \multicolumn{1}{|c}{$\begin{array}{c}\text { Metaforización } \\
\text { representadora }\end{array}$} & \multicolumn{1}{c}{ Sentidos inferenciales } \\
\hline $\begin{array}{l}\text { Los pobres de } \\
\text { Guadalajara }\end{array}$ & $\begin{array}{l}\text { «..la corte de los mi- } \\
\text { lagros» }\end{array}$ & $\begin{array}{l}\text {-Podemos inferir que topical- } \\
\text { mente se hace alusión al título de } \\
\text { la novela La corte de los mila- } \\
\text { gros, de Ramón María del Valle } \\
\text { Inclán, donde se relatan numero- } \\
\text { sos hechos de falsedad, abuso y } \\
\text { codicia entre clases bajas y altas, } \\
\text { precisamente en el entorno de la } \\
\end{array}$ \\
& $\begin{array}{l}\text { corte que rodeaba a Isabel II. } \\
\text {-En la época parece claro que } \\
\text { la frase aludía a quienes solían } \\
\text { aprovecharse del éxito ajeno. }\end{array}$ \\
& $\begin{array}{l}\text { «...y difícilmente se } \\
\text { recorre una acera sin } \\
\text { que el transeúnte se } \\
\text { vea asaltado por una } \\
\text { legión de mendigos» }\end{array}$ & $\begin{array}{l}\text {-Los mendigos pueden estar en } \\
\text { cualquier lugar. } \\
\text {-Pueden robar. } \\
\text {-Actúan en grupos numerosos. }\end{array}$ \\
\hline
\end{tabular}




\begin{tabular}{|c|c|c|}
\hline $\begin{array}{l}\text { Actores } \\
\text { sociales }\end{array}$ & $\begin{array}{l}\text { Metaforización } \\
\text { representadora }\end{array}$ & Sentidos inferenciales \\
\hline & $\begin{array}{l}\text { «...verdaderos y fal- } \\
\text { sos» }\end{array}$ & $\begin{array}{l}\text {-Atribuciones actitudinales muy } \\
\text { antiguas y de amplio consenso, } \\
\text { esto es, que hay personas sin otra } \\
\text { alternativa más que la mendici- } \\
\text { dad y personas que se vuelven } \\
\text { mendigos para no trabajar for- } \\
\text { malmente. }\end{array}$ \\
\hline & $\begin{array}{l}\text { «...turba de niños y } \\
\text { niñas que por don- } \\
\text { de quiera tienden las } \\
\text { manos implorado- } \\
\text { ras» }\end{array}$ & $\begin{array}{l}\text {-Aquí se pone en juego una do- } \\
\text { ble presuposición, mediante el } \\
\text { nominal de carácter despectivo } \\
\text { turba: } a \text { ) no se trata de niños } \\
\text { agrupados pacíficamente, sino } \\
\text { en disposición de alterar y } b \text { ) no } \\
\text { son pocos los que alteran el or- } \\
\text { den para pedir dinero. } \\
\text {-Nótese como se destaca exclu- } \\
\text { sivamente el rol pasivo-agresivo } \\
\text { de los niños. }\end{array}$ \\
\hline & $\begin{array}{l}\text { «Y a propósito, de- } \\
\text { biera ésta [la poli- } \\
\text { cía] poner cuanto } \\
\text { antes su atención en } \\
\text { este desdichadísimo } \\
\text { asunto de los pordio- } \\
\text { seros que inundan la } \\
\text { ciudad» }\end{array}$ & $\begin{array}{l}\text {-Aquí, por partida doble, las ma- } \\
\text { nipulaciones inferenciales, de- } \\
\text { penden de dos estrategias mag- } \\
\text { nificadoras: } a \text { ) otorgar carácter } \\
\text { personificador a un fenómeno: } \\
\text { desdichadísimo asunto; } b \text { ) hacer } \\
\text { que un conjunto de personas ten- } \\
\text { ga atributos donde la superficie } \\
\text { que hace de recipiente (la ciudad) } \\
\text { se corresponde con el contenido } \\
\text { (los pordioseros), y c) el modo } \\
\text { en que el recipiente «ciudad» es } \\
\text { inundado, evoca la violencia de } \\
\text { caudales incontenibles, capaces } \\
\text { de provocar catástrofes.12 }\end{array}$ \\
\hline
\end{tabular}

12 En este caso se cumple negativamente la sentencia de Lakoff y Johnson «conforme hacemos un argumento se crea más superficie» (1995:135), es decir, en la medida en que se implica que hay más pobres, también se implica, a través de inundar, que los pobres abarcan mayor superficie de la ciudad. 
El último ejemplo es una muestra de la importancia que tiene la cohesión a nivel metafórico. Tanto inundan, como la ciudad, son metaforizaciones coherentes entre sí, pues hacen las funciones de contenido y continente. De manera que ambas se complementan, ya que una sola no sería suficiente para desempeñar las dos funciones al mismo tiempo.13 Además son consistentes entre sí, ya que actuando como dos conceptos diferentes, facilitan el cumplimiento de un solo objetivo, claramente delineado, que es el de enfatizar los peligros a los que se puede exponer cualquier habitante de la ciudad si se topa con un grupo de personas que piden limosna.

Si planteamos el hecho de que la consecución de un objetivo enunciativo, depende de la cohesión y la consistencia, por lo menos entre dos conceptos metafóricos que entran en juego, entonces vale la pena señalar que la cohesión metafórica suele ser analizada desde dos perspectivas: la abstraccionista y la homonimia. Desde la perspectiva abstraccionista, cuando se establecen relaciones de sentido entre dos conceptos metafóricos, provenientes de diferentes campos, lo que tenemos es un mismo concepto abstracto de base, aplicado en dos campos distintos. Pero desde la perspectiva homonímica, lo que tenemos no es un sólo concepto abstracto que opera en dos metáforas distintas, sino dos conceptos diferentes e independientes (X1 y X2). Lakoff y Johnson (1995:147) muestran esta diferencia con dos ejemplos:

«reforzó la pared»

«reforzó su argumento con más hechos»

Para los abstraccionistas, en ambos casos se comparte el mismo concepto abstracto reforzar. Desde el punto de vista homonímico, lo que tenemos son dos conceptos independientes, pues uno se refiere a un objeto físico la pared y el otro a un concepto abstracto su argumento. A nosotros nos ha parecido adecuado asumir una posición intermedia, es decir, si tenemos un concepto metafórico (X1), homónimo de un con-

13 De hecho Lakoff y Johnson afirman que una metáfora no puede desempeñar simultáneamente las funciones de argumento y recipiente, cuando la pretensión no es mezclar dos objetivos intensificadores (1995:135). 
cepto metafórico (X2), vamos a considerar que se trata de conceptos distintos e independientes, pero relacionados entre sí, bajo el orden de semejanzas abstractas y parciales. Este último aspecto es de gran importancia, ya que, como han demostrado Lakoff y Johnson las metáforas no comparten entre sí un mismo concepto, lo suficientemente abstracto como para que se ajuste a todos los aspectos de los campos semánticos que entran en juego (ibid.:149-151). Lo que tenemos, más bien, es un sistema de aspectos compartidos, donde los conceptos menos delineados, que normalmente suelen ser menos concretos, ceden por decirlo así, su lugar a conceptos que podemos delinear más fácilmente, según la finalidad que nos propongamos. Así, en el último ejemplo de las agrupaciones metafóricas que mostramos, si el locutor ha pretendido enfatizar la gran cantidad de personas que pedían limosna en las calles, así como la fuerza y la insistencia con que lo hacían, parece más aceptable en términos de efectividad decir que los mendigos inundan, y no que mojan, humedecen o salpican. Este principio selectivo también genera dirección metafórica, pues la base de su construcción radica en el hecho de que las personas tendemos a estructurar lo que es menos concreto mediante similitudes provenientes de conceptos más concretos, más delineables, y además, tendemos a satisfacer los principios básicos de forma y contenido, vinculados entre el concepto metafórico y los referentes. ${ }^{14}$ Cuando se dice que los mendigos inundan la ciudad, se plantea una relación espacial entre forma y contenido. Entre más forma tengamos, las expectativas de contenido han de ser mayores.

Otra estrategia metafórica que influye en la cohesión textual está dada por la proximidad o lejanía sintáctica que hay entre ellas. La contigüidad entre dos expresiones metafóricas deriva en un efecto intensificador del sentido, de manera que se produce una relación estrecha, casi simbiótica, entre forma y significado. Nos parece que Lakoff y Johnson explican este fenómeno de manera muy clara:

14 Aunque es verdad que aún no se desarrolla una teoría del todo convincente que explique detalladamente cómo es que se produce este fenómeno que Lakoff y Johnson llaman «homonimia débil» (1995:155). El enorme problema radica en que aún hay muchas áreas de nuestra experiencia que no se han definido del todo, a partir de sus propios términos; lo tienen que hacer a partir de otras áreas de la experiencia. 
Si el significado de la forma $A$ afecta al significado de la forma $B$, entonces, cuanto más próxima está la forma $A$ de la forma $B$, el efecto del significado de $A$ sobre el significado de $B$ será más fuerte (ibid.:170).

En nuestro corpus se hace evidente que esta estrategia de proximidad sintáctica es relevante, en la medida en que sirve para intensificar efectos peyorativos y discriminadores. Tiene un rango de afectación a distintos niveles en la representación sesgada de actores, además puede intensificar la percepción cognitiva de situaciones genéricas, cuya representación en abstracto suele estar muy topicalizada. Tal es el caso de percepciones abstractas como pobreza, miseria, riqueza, bienestar, bueno, malo, etc. Veamos el siguiente ejemplo tomado del mismo reportaje que hemos estado analizando:

(13) «pero hay una turba de niños y niñas que por donde quiera tienden las manos imploradoras, adoptan una actitud dolorida e hipócrita y son predestinados a una vida de vergüenza y de abyección»

Es notable la función reforzadora de menor a mayor intensidad en el par de secuencias atribucionales dolorida-hipócrita, así como en la secuencia vergüenza-abyección. Cabe notar que en éste, como en muchos otros casos, la proximidad sintáctica se produce en cumplimiento de uno de los principios básicos de esta estrategia intensificadora, a saber que la relación de contigüidad se produce de manera paradigmática, es decir, si un término es substituido por otro en la misma secuencia, se sigue preservando la cohesión sintáctica y el sentido del enunciado (Feder, 1987:231). Aquí es clave el contexto, ya que se trata de colocar significados en acción y sobre todo, como en estos casos (13), se trata de provocar efectos en la percepción de los lectores. Como parámetros de uniformidad, estas series secuenciales de conceptos metafóricos (dolorida-hipócrita, vergüenza-abyección), son lo suficientemente específicas y genéricas al mismo tiempo, como para generar expectativas de sentido cíclico. De manera que podemos presuponer que al locutor le interesa destacar el hecho de que las actitudes de los mendigos se repiten una y otra vez. 
Además del carácter cíclico se ha destacado la función sucesora como elemento esencial de cohesión metafórica, pues toda vez que se ha establecido una cierta regularidad secuencial entre diversas metáforas, podemos asegurar que estamos ante la constitución activa de un campo semántico, que en un contexto como el que estamos analizando, no sólo opera como un dispositivo persuasivo, sino como una forma de estructurar las condiciones de verdad que se quieren imponer, por ejemplo, que en todos los casos los mendigos son en sí mismos un problema. Este es un hecho típico de pragmática textual. Cuando el discurso intenta problematizar a otros, un recurso socorrido consiste en generar la expectativa de que la verdad de ciertos fenómenos se preserva en todos los contextos y con todas las convenciones relevantes propias de un contexto $n$, tales como el conjunto de creencias, y presuposiciones involucradas entre los miembros a donde pertenecen hablantes y receptores (ibid::237). Esto ocurre también porque ciertos términos secuenciales, como los mencionados (dolorida-hipócrita, vergüenza-abyección) aparecen dispuestos bajo el aparente juego de los hipónimos. Sin embargo, la hiponimia, basada en la inclusión de categorías dentro de otras, en un orden lógico de clases, es apropiada para conceptos extensivos como ocurre en biología. Sin embargo, en un texto de carácter persuasivo la hiponimia no opera para generar mayor comprensión ni sistematicidad, como ocurre en las taxonomías científicas, donde los contrastes permiten conocer rangos de operatividad y variación. Pero en series secuenciales como la recién citada (dolorida-hipócrita, vergüenza-abyección), tenemos, en palabras de Eva Feder Kittay: «There are gaps, asymmetries, and indeterminacies in lexical areas» (ibid::239). Esto ocurre a pesar de que al mismo tiempo en una serie como ésta debe haber cierta relación sistemática y sobre todo porque se trata de un claro ejemplo donde opera el principio formulado por John Searle cuando afirma que el conocimiento que posibilita a los receptores de mensajes, «usar»y «entender» el sentido metafórico va más allá del conocimiento literal de palabras y sentencias (1995:84). Pero además hay otra razón de peso por la cual esta serie de pares secuenciales no sirven para explicar, sino más bien para persuadir. En pares como (dolorida-hipócrita, vergüenzaabyección) no tenemos una relación antipodal, que permita reconocer extremos opuestos como norte-sur, dulce-salado, alegre-triste, etc. Tam- 
poco tenemos una relación escalar que permita reconocer jerarquías del tipo soldado, sargento, capitán, mayor, etc. Lo que tenemos es una serie ortogonal (Feder, 1987:243) que no está estructurada para determinar, sino para evaluar.

(14) «Es indígena puro y, además. Incivil y desgarbado, debido quizás a su vida obscura y descuidada. Nace a la buena de Dios...» (Revista Jalisco Rural, 1923).

Tengamos en cuenta que una evaluación metafórica en general no depende exclusivamente del plano semántico, sino del grado de suposiciones que el receptor pueda lograr. En este último ejemplo (14) parece claro que las metaforizaciones subrayadas están ligadas con series de construcciones de amplia circulación y aceptación en la época, indudablemente vinculadas con la tradición colonial de segregación y menosprecio de los indígenas en América Latina. Así, vemos de nuevo cómo es que la metaforización tenía gran importancia en los procedimientos de representación conflictiva y discriminadora de ciertos actores sociales, que en el discurso de la prensa tapatía de principios del siglo XX, eran considerados inferiores, problemáticos, amenazantes, indeseables o simplemente anormales.

A manera de conclusión podemos decir que la metaforización formaba parte de una serie de estrategias discursivas, de gran importancia en la representación conflictiva y discriminadora de ciertos actores sociales, que en el discurso de la prensa tapatía de principios del siglo XX, eran considerados inferiores, problemáticos, amenazantes, indeseables o anormales. Mostramos cómo es que las metáforas funcionaban como actos de habla especiales, proclives a la consecución de ciertas funciones de refuerzo estigmatizante y discriminador.

Al cobijo de las teorizaciones ontológicas sobre metáfora de Lakoff y Johnson, vimos cómo en muchas ocasiones los enunciados metafóricos no sólo se limitaban a orientar maneras negativas de representar, además, también orientaban a los lectores para inducirlos a actuar de manera agresiva contra personas que no eran bien vistas por los grupos sociales de mayor poder económico y político. En ese sentido se trataba de actos de habla especiales que requerían por lo menos tres niveles 
articulados, los cuales hemos llamado refuerzos: un primer refuerzo focalizador (el lector es inducido a centrar su atención sólo en aquellos aspectos considerados relevantes por diversas instancias de autoridad); un segundo refuerzo categorizador (el lector es inducido a concebir aquello de lo que se habla en función de categorías predeterminadas), y por último, un refuerzo orientador (el lector es inducido a proyectar una orientación sobre algo que no posee orientación de manera inherente).

Por otro lado, a la luz de las reflexiones de Eva Feder observamos cómo es que las metaforizaciones proporcionaban indicios «sintomáticos de diagnóstico» respecto al objeto (1987:187). Así era posible establecer conjuntos de redes presuposicionales que intentan dar cuenta de una serie amplia de «maneras de ser» tan abarcadoras como el carácter de las personas, costumbres, afinidades, competencias, etc. Finalmente observamos que en las relaciones de sentido metafórico eran decisivas las estrategias cohesionadoras de sentido, tanto anafóricas como catafóricas. Cuando tenemos una metáfora de representación negativa, es porque anteriormente ya había aparecido un item de significación semejante. De igual modo, una metáfora de representación negativa, también anticipaba distintos niveles de lo que posteriormente vendría en el discurso.

\section{Bibliografía}

ANDREW, Richard (1965) «The origins of facial expressions». En Scientific american, 213.

ARGYLE, Michael (1969) Social interaction. Londres: Methuen.

Austin, John (1962) How to do things with words. Oxford: Oxford University Press.

BARWISE, Jon y John Perry (1983) Situations and attitudes. EU: The Massachusetts Institute of Technology.

BEARDLSLEY, M. C. (1958) Aesthetics: problems in the ohilosophy and phenomenologycal research. Nueva York: Harcourt Brace.

BENVENISTE, Émile (1987) «Metaphor and the semantics of the word».

En Paul Ricoeur (comp.) The rule of metaphor. Multidisciplinary studies of the creation of meaning in language. Canadá: University of Toronto Press.

CAMERON, Lynne (2003) Metaphor in educational discourse. LondresNew York: Continuum. 
CHEVAlIER, Jean y Alain Gheerbrant (1995) Diccionario de los símbolos. Traducido por Manuel Silvar y Arturo Rodríguez. Barcelona: Herder.

DAVEY, A. G. (1970) «How subliminal is your persuasion». En New society. 21 de mayo.

DEIGNAN, Alice (2005) Metaphor and corpus linguistics. Ámsterdam: John Benjamins.

Eco, Umberto (1998) Los límites de la interpretación. Traducido por Helena Lozano. Barcelona: Lumen.

EL INFORMADOR, 6 de octubre de 1917; 15 de noviembre de 1918; 25 de marzo de 1938. Guadalajara, Jalisco.

ENCICLOPEDIA MICROSOFT ENCARTA (2001) «Homosexualidad».

EKMAN, Paul; Wallace, Friesen y Phoebe Ellsworth (1971) Emotion in the human face. Nueva York: Pergamon.

FEDER Kittay, Eva (1987) Metaphor. Its cognitive force and linguistic estructure. Oxford: Clarendon Press.

Foucault, Michel (2001) Historia de la sexualidad, Vol. 2. El uso de los placeres. Traducido por Martí Soler. México: Siglo XXI.

GIBBS, Raymond (1994) The poetics of mind. Cambridge: Cambridge University Press.

GIORA, Rachel (2003) On our mind: salience, context, and figurative language. Nueva York: Oxford University Press.

GOATLY, Andrew (1997) The language of metaphors. Londres: Routledge.

Goodman, N. (1984) Of mind and other matters. Cambridge: Harvard University Press.

GoOSSENS, Louis (1995) «Metaphtonymy: the interaction of metaphor and metonymy in figurative expressions of linguistic action». En Louis Goossens et al. By word of mouth: metaphor, metonymy and linguistic action in a cognitive perspective. Ámsterdam: Benjamins/ Chicago Press.

LAKOFF, George y Mark Johnson (1995) Metáforas de la vida cotidiana. Traducido por Carmen González Marín. Madrid: Cátedra.

ORTONY, Andrew (1975) «Why metaphors are necessary and not just nice». En Educational theory, 25. Cambridge: University Press.

- (ed.) (1993) Metaphor and thought. Cambridge: Cambridge University Press. 
PARENTE, Diego (2000) «Literalidad, metáfora y cognición. Observaciones escritas sobre la perspectiva experiencialista de G. Lakoff y M. Johnson». En Revista A Parte Rei, 11. Noviembre. Madrid.

PEREGRín Otero, Carlos (2000) «Pronombres reflexivos y recíprocos». En Gramática descriptiva de la lengua española, Tomo 1. Madrid: Real Academia Española/Espasa-Calpe.

RAIBLE, Wolfgang (2004) «¿Qué es un texto?». En Revista Función, 21-24. Guadalajara, México.

REVISTA Jalisco Rural (1923) Julio.

Rosch, Eleanor (1977) «Human categorization». En Advances in crosscultural psychology, 1. Nueva York: Academic Press/N. Warren.

SEARLE, John R. (1995) «Metaphor». En Andrew Ortony (ed.) Metaphor and thought. Cambridge: Cambridge University Press.

SEBEOK, Thomas A. (1996) Signos: una introducción a la semiótica. Traducido por Pilar Torres. Barcelona: Paidós.

SCHEFFLER, I. (1979) Beyond the letter: a philosophical inuiry into ambiguity, vagueness, and methaphor in language. Londres: Routledge/Kegan Paul.

STRAWSON, P.F. (1989) Individuos. Madrid: Taurus.

TAUB, Sara (2001) Language from the body: iconicity and metaphor in american sign language (hardcover). Cambridge: Cambridge University Press.

TURNER, Mark «Design for a theory of meaning». En http://www.oregon/metaphor.

WHORF, Benjamin (1956) Language, thought, and reality: selected writings of benjamin Lee Whorf. Cambridge: MIT Press. 